\title{
Direct Torque Control Using Phase Current Reconstruction Algorithm In Induction Motor
}

\author{
Anju R ${ }^{1}$ Sathiskumar $\mathrm{M}^{2}$ \\ ${ }^{1}$ M.E Power Electronics and Drives, Department of PG-Electrical sciences, P.A.College of Engineering and Technology. \\ ${ }^{2}$ Associate professor HOD, Department of PG-Electrical sciences, P.A.College of Engineering and Technology.
}

\begin{abstract}
In this paper, a low-cost high-performance Induction Motor (IM) drive using Direct Torque Control (DTC) is obtained by simple algorithm using reconstruction of phase current. By using the details acquired from one shunt resistor this algorithm is developed. The proposed algorithm is very simple and robust. Stator currents were used to estimate motor flux and torque in previous works. In this algorithm the stator currents are replaced by dc current. A theoretical concept is developed for DTC based induction motor drive. The performance is simulated using MATLAB/SIMULINK software.
\end{abstract}

Index Terms: Direct Torque Control (DTC), Induction Motor (IM), sensor count reduction, single current sensor.

\section{Introduction}

Induction Motors (IMs) are widely used in industrial, commercial and domestic applications as they are simple, rugged, low cost and easy to maintain. Since IMs demands well control performances: precise and quick torque and flux response, large torque at low speed, wide speed range, the drive control system is necessary for IMs. Though DC motor is able to provide desired performance, its maintenance and unsafe in explosive environment restricts its use. In 1970s, field oriented control (FOC) scheme proved success for torque and speed control of induction motor. Decoupling of two components of stator currents (flux and torque producing components) is achieved as DC machines to provide independent torque control. Hence the scheme proves itself superior to the DC machine. The problem faced by FOC scheme is complexity in its implementation due to dependence of machine parameters, reference frame transformation. Later DTC was introduced. The method requires only the stator resistance to estimate the stator flux and torque.

In conventional DTC, electromagnetic torque and flux are independently controlled by selection of optimum inverter switching modes. The selection of optimum inverter switching modes is made to limit the electromagnetic torque and flux linkage errors within the torque and flux hysteresis bands. Every control method has some advantages and disadvantages, DTC method has too. Some of the advantages are lower parameters dependency, making the system more robust and easier implements and the disadvantages are difficult to control flux and torque at low speed, current and torque distortion during the change of the sector, variable switching frequency, a high sampling frequency needed for digital implementation of hysteresis controllers, high torque ripple. The torque ripple generates noise and vibrations, causes errors in sensor less motor drives, and associated current ripples are in turn responsible for the EMI. The reason of the high current and torque ripple in DTC is the presence of hysteresis comparators together the limited number of available voltage vectors.

In this paper, we propose a low-cost single shunt current sensor induction motor (IM) DTC. The stator flux vector and the electromagnetic torque are directly calculated from the voltage and the current derived from a single dc-link voltage sensor (simple voltage divider) and a single dc-link current sensor (simple shunt resistor). The phase currents are estimated by two dc-link current measurement processes. This algorithm does not require additional computation burden or other motor parameter knowledge

\section{Direct Torque Control}

DTC uses a simple switching table to determine the most opportune inverter state to attain a desired output torque [1]. By means of current and voltage measurements, it is possible to compute approximately the instantaneous stator flux and output motor torque. The control algorithm based on flux and torque hysteresis controllers determines the voltage required to drive the flux and torque to the desired values within a fixed time period. The fundamental functional blocks used to implement the DTC scheme are represented in Figure. 1.

The stator flux vector $\vec{\phi}_{s}$ and the torque produced by the motor, $\Gamma$ em, can be estimated. These equations only require the knowledge of the previously applied voltage vector $V_{s}$, measured stator current $I_{s}$, stator resistance $R_{s}$, and the motor poles number $p$. 


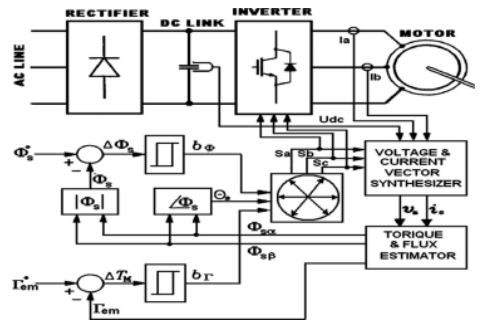

Figure 1 Conventional DTC System

The stator voltage polar components $\left(\mathrm{V}_{\mathrm{s} a}, \mathrm{~V}_{\mathrm{s \beta}}\right)$ on perpendicular $(\alpha, \beta)$ reference frame result from measured dclink voltage $\mathrm{U}_{\mathrm{dc}}$ and the switching controls logical states $S_{a}, S_{b}$, and $S_{c}$ are given by,

$$
\left\{\begin{array}{l}
V_{s \alpha}=\sqrt{\frac{2}{3}} U_{d c}\left(S_{a}-\frac{1}{2\left(S_{b}-S_{c}\right.}\right) \\
V_{S \beta}=1 / \sqrt{2} U_{d c}\left(S_{b}-S_{c}\right)
\end{array}\right.
$$

and stator current components $\left(I \alpha, I_{\beta}\right)$

$$
\left\{\begin{array}{l}
I_{S \alpha}=\sqrt{3 / 2} I_{a} \\
I_{S \beta}=1 / 2 \sqrt{\left(I_{b}-I_{c}\right)}
\end{array}\right.
$$

The stator resistance can be assumed constant. During a switching period, the voltage vector applied to the motor is constant. By integrating the back electromotive force (EMF), the stator flux can be estimated using

$$
\left\{\begin{array}{c}
\phi_{s \alpha}=\int\left(V_{s \alpha}-R_{s} I_{s \alpha}\right) d t \\
\phi_{s \beta}=\int\left(V_{s \beta}-R_{s} I_{s \beta}\right) d t
\end{array}\right.
$$

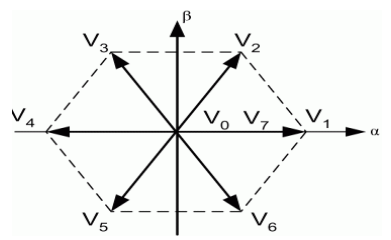

Figure 2 Vectors in DTC

Table 1 Basic DTC Switching Table

\begin{tabular}{|c|c|c|c|c|c|c|c|}
\hline $\mathbf{b}_{\Phi}$ & $\mathbf{b}_{\mathbf{r}}$ & $\begin{array}{c}\text { Sector } \\
\text { I }\end{array}$ & $\begin{array}{c}\text { Sector } \\
\text { II }\end{array}$ & $\begin{array}{c}\text { Sector } \\
\text { III }\end{array}$ & $\begin{array}{c}\text { Sector } \\
\text { IV }\end{array}$ & $\begin{array}{c}\text { Sector } \\
\text { V }\end{array}$ & $\begin{array}{c}\text { Sector } \\
\text { VI }\end{array}$ \\
\hline \multirow{3}{*}{1} & $\mathbf{1}$ & $\mathbf{V}_{5}$ & $\mathbf{V}_{6}$ & $\mathbf{V}_{1}$ & $\mathbf{V}_{2}$ & $\mathbf{V}_{3}$ & $\mathbf{V} 4$ \\
\cline { 2 - 8 } & $\mathbf{0}$ & $\mathbf{V}_{3}$ & $\mathbf{V}_{4}$ & $\mathbf{V}_{5}$ & $\mathbf{V}_{6}$ & $\mathbf{V}_{1}$ & $\mathbf{V}_{2}$ \\
\hline \multirow{2}{*}{0} & 1 & $\mathbf{V}_{6}$ & $\mathbf{V}_{1}$ & $\mathbf{V}_{2}$ & $\mathbf{V}_{3}$ & $\mathbf{V}_{4}$ & $\mathbf{V}_{5}$ \\
\cline { 2 - 8 } & $\mathbf{0}$ & $\mathbf{V}_{2}$ & $\mathbf{V}_{3}$ & $\mathbf{V}_{4}$ & $\mathbf{V}_{5}$ & $\mathbf{V}_{6}$ & $\mathbf{V}_{1}$ \\
\hline
\end{tabular}

During the switching period, each voltage vector is constant and (5) is then rewritten as

$$
\left\{\begin{array}{l}
\phi_{s \alpha}=\phi_{s \alpha}+\left(V_{s \alpha}-R_{s} I_{s \alpha}\right) T_{s} \\
\phi_{s \beta}=\phi_{s \beta}+\left(V_{s \beta}-R_{s} I_{s \beta}\right) T_{s}
\end{array}\right.
$$

Where $T_{\mathrm{s}}$ is the control loop period. 
The magnitude of the stator flux can be estimated by,

$$
\phi_{s}=\sqrt{\left(\phi_{s \alpha}+\phi_{s \beta}\right)^{2}}
$$

We can find the flux vector zone using the stator flux components $\left(\phi_{s \alpha}, \phi_{s \beta}\right)$.By using the flux components, current components and IM number of poles, the electromagnetic torque can be calculated by

$$
\tau_{e m}=3 / 2 p\left(\phi_{s \alpha} I_{s \beta}-\phi_{s \beta} I_{s \alpha}\right)
$$

As shown in Figure 2, six equally spaced voltage vectors having the same amplitude and two zero voltage vectors are the only switching combinations, which can be chosen for an inverter operation. The selection of a voltage vector is made to preserve the torque and the stator flux inside the hysteresis bands limits. The switching table is given by Table I.

\section{DTC Using Single Current Sensor}

The conventional DTC scheme requires two current sensors at least. The proposed DTC scheme described in this paper uses only one shunt resistor for dc-link current measurement as revealed on Figure 3. For this purpose, a suitable method to reconstruct the phase currents and voltages is devised with a simple modification of the basic DTC scheme using zone shift strategy. Two modifications of the basic DTC are used for estimating the three-phase currents from a single dc-link current sensor. On the first modification, the control system should be able to generate more voltage vectors.

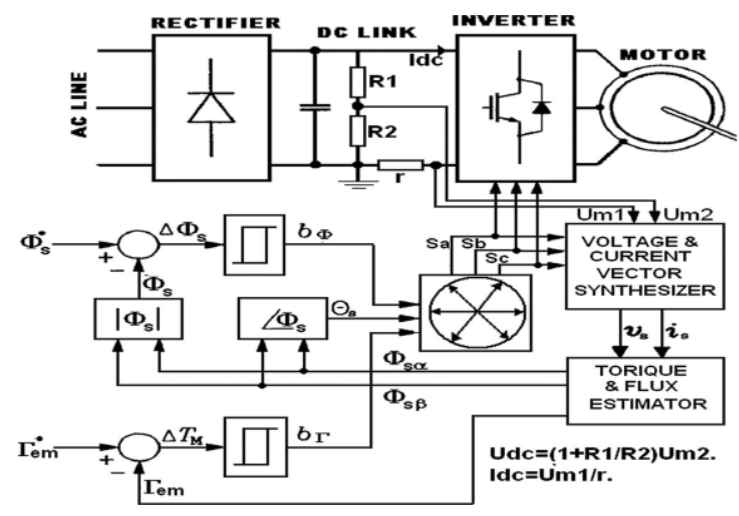

Figure 3 Proposed DTC Scheme.

\section{Reconstruction Of Stator Current And Dc-Link Current Sampling}

One of the most important purposes for single-shunt three phase reconstructions is to reduce the cost. This, in turn, simplifies the sampling circuit to one shunt resistor and some other electronic components. Moreover, the single-shunt algorithm allows the use of power modules that do not provide, for each phase, individual ground connection. Another single-shunt measurement advantage is that the same circuit is being used to sense all three phases. For all measurements, the gains and offset will be the same, which eliminate the software calibration of each phase measurement structure.

\section{A)DC Current Measurement}

The sampling circuit of dc-link current using single shunt resistor in an usual three-phase power voltage source inverter is used. A measurement shunt resistor is placed between the lower side power switches emitter terminals and the negative dc bus rail that is connected to the ground. The voltage drop across the shunt resistor is amplified and level shifted. In the case of non isolated grounds between control circuit and power circuit, the signal is sent directly to the analog-to-digital converter (ADC) inputs of a digital signal. 


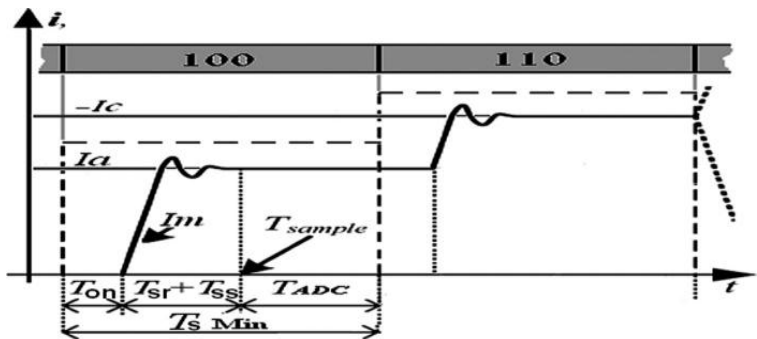

Figure 4 Recurred Sampling Time.

Table II DTC Voltage Vector Measurement Of Phase Current

\begin{tabular}{|c|c|}
\hline Active Voltage Vector & DC-link Current \\
\hline $\mathrm{V}_{1}$ & Ia \\
\hline $\mathrm{V}_{2}$ & -Ic \\
\hline $\mathrm{V}_{3}$ & $\mathrm{Ib}$ \\
\hline $\mathrm{V}_{4}$ & -Ia \\
\hline $\mathrm{V}_{5}$ & Ic \\
\hline $\mathrm{V}_{6}$ & -Ib \\
\hline
\end{tabular}

B)Reconstruction of Phase current

In the classical DTC, for each active voltage vector, there is only one current flowing in the dc link, which could be measured. Table III illustrates according to the switch states the relationship between the dc-link current and the phase currents.

\section{Simulation Work And Results}

A three phase supply of $460 \mathrm{~V}, 60 \mathrm{~Hz}$ is fed to DTC based IM drive is shown in Figure 5. Stator current, speed, torque and DC bus voltage are taken as output.

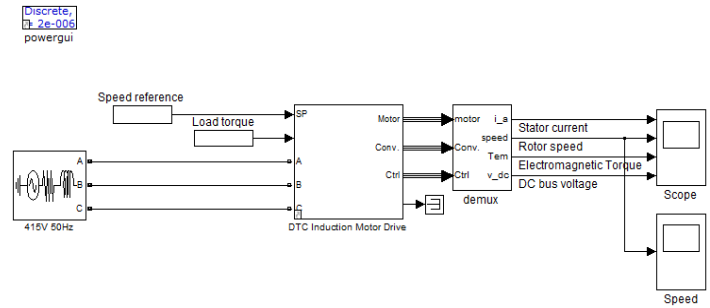

Figure 5 Overview of DTC Method

A three phase supply is given to rectifier block to get DC output which is fed to inverter to get variable voltage supply. This supply is fed to induction motor and speed and torque are taken as output. Reference speed and actual speed are compared to generate reference torque is shown in Figure 6.

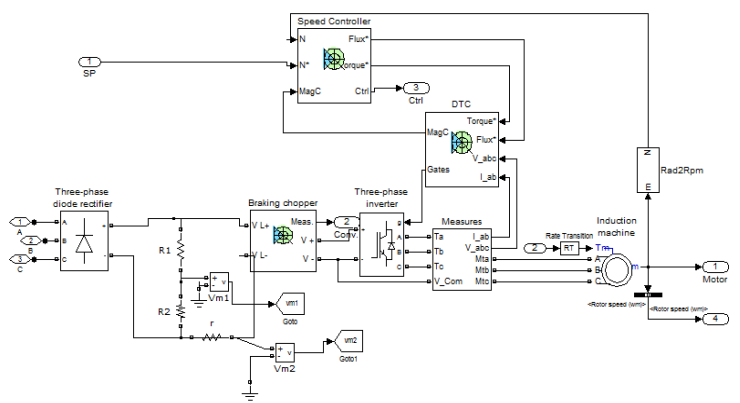

Figure 6 Subsystem of DTC-IM

DC link current and voltage are used to produce actual torque and flux of IM. The actual values are compared with reference values and fed to Hysteresis controller to produce voltage vectors as shown in Figure 7. 


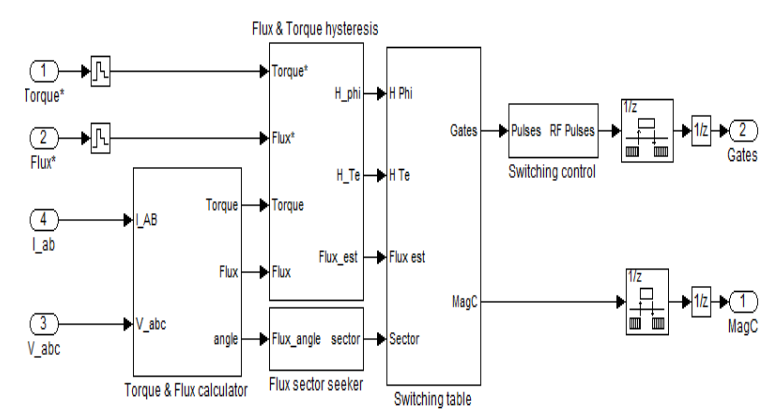

Figure 7 Mask of DTC

Actual speed is taken to calculate the reference flux. Actual speed and reference speed are compared using PI controller to produce reference torque is shown in Figure 8.

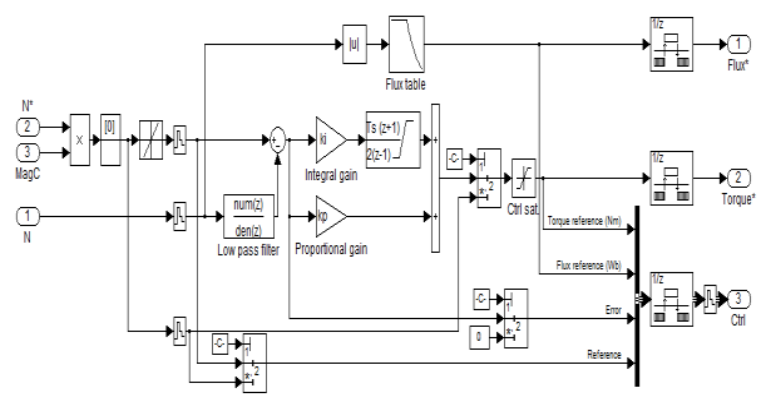

Figure 8 Mask of Speed Controller

The output of Stator current, rotor speed, torque and DC bus voltage are shown in Figures 9,10,11, and 12.

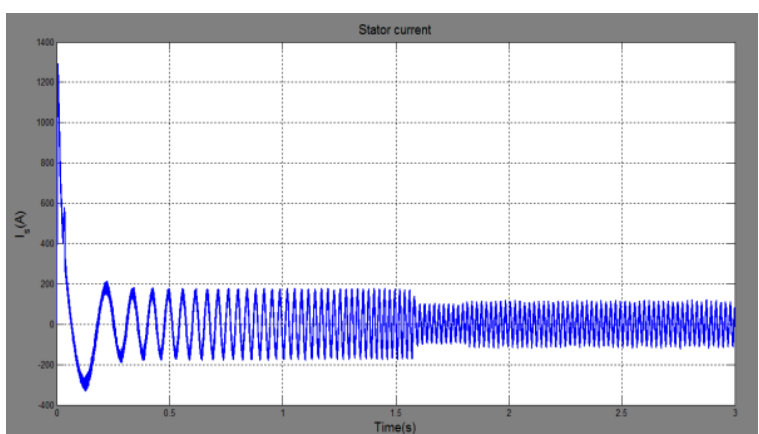

Figure 9 Output for Stator Current

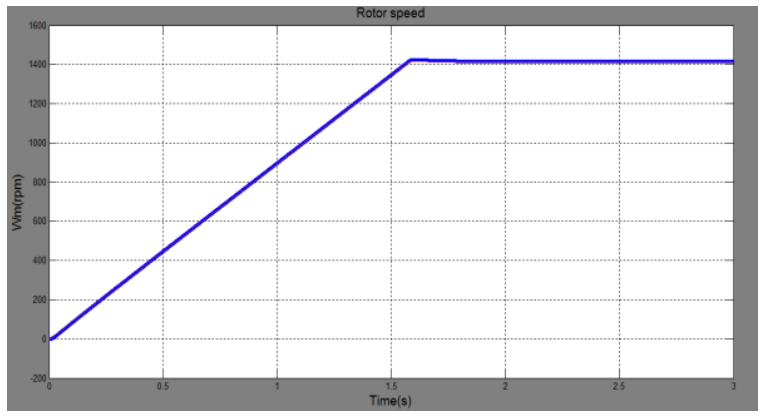

Figure 10 Output for Rotor Speed 


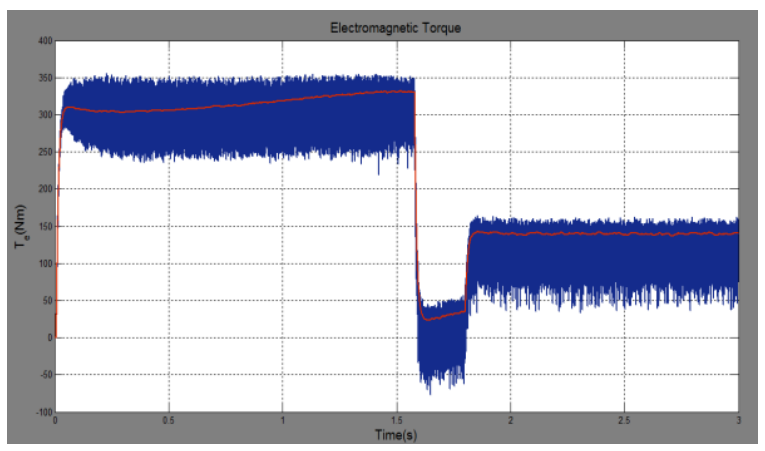

Figure 11 Output for Electromagnetic Torque

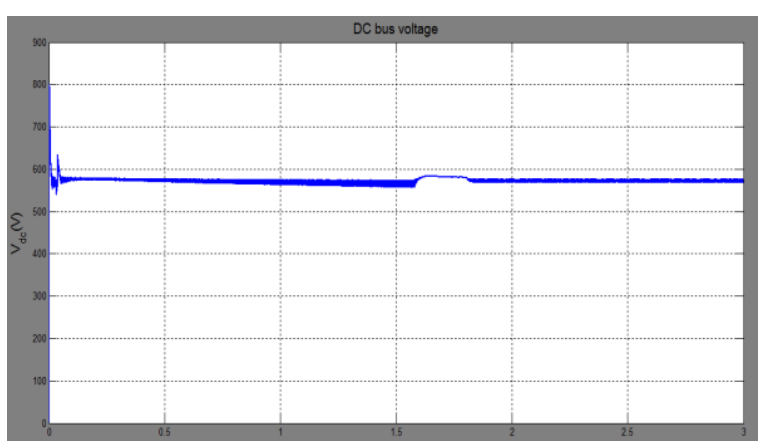

Figure 12 Output for DC bus voltage

\section{Conclusion}

In this paper, phase-current reconstruction has been presented using a single shunt resistor inserted in the dc-link path. The stator currents needed to estimate the stator flux magnitude and the electromagnetic torque is reconstructed by means of a simple modification in the conventional DTC system. A two-interval discrete space vector modulation technique is used to generate the six active voltage vector needed for dc-link current measure without changing the DTC strategy. So the performance is similar to the conventional DTC method.

\section{References}

[1] I. Takahashi and T. Noguchi, "A new quick response and high-efficiencycontrol strategy of an induction motor," IEEE Trans. Ind. Appl., vol. IA-22, no. 5, Sep./Oct. 1986.

[2] S. A. Zaid, O. A. Mahgoub, and K. El-Metwally, "Implementation of anew fast direct torque control algorithm for induction motor drives," IETElectr. Power Appl., vol. 4, no. 5, May 2010.

[3] C. Patel, R. P. P. A. Day, A. Dey, R. Ramchand, K. K. Gopakumar, andM. P. Kazmierkowski, "Fast direct torque control of an open-end inductionmotor drive using 12-sided polygonal voltage space vectors," IEEE Trans.Power Electron., vol. 27, no. 1, Jan. 2012.

[4] Y. Zhang and J. Zhu, "Direct torque control of permanent magnet synchronousmotor with reduced torque ripple and commutation frequency,"IEEE Trans. Power Electron., vol. 26, no. 1, pp. 235-248, Jan. 2011.

[5] Y. Zhang and J. Zhu, "A novel duty cycle control strategy to reduce bothtorque and flux ripples for DTC of permanent magnet synchronous motordrives with switching frequency reduction," IEEE Trans. Power Electron.,vol. 26, no. 10, pp. 3055-3067, Oct. 2011.

[6] K. D. Hoang, Z. Q. Zhu, andM. P. Foster, "Influence and compensation ofinverter voltage drop in direct torque-controlled fourswitch three-phasePM brushless AC drives," IEEE Trans. Power Electron., vol. 26, no. 8, Aug. 2011.

[7] S. Bolognani, L. Peretti, and M. Zigliotto, "Online MTPA control strategyfor DTC synchronous-reluctance-motor drives," IEEE Trans. PowerElectron., vol. 26, no. 1, pp. 20-28, Jan. 2011.

[8] G. Foo and M. F. Rahman, "Direct torque and flux control of an IPMsynchronous motor drive using a backstepping approach," IET Elect.Power Appl., vol. 3, no. 5, pp. 413-421, Sep. 2009.

[9] M. E. Haque and M. F. Rahman, "Incorporating control trajectorieswith the direct torque control scheme of interior permanent magnet synchronousmotor drive," IET Elect. Power Appl., vol. 3, no. 2,Mar. 2009.

[10] F. Blaabjerg, J. K. Pedersen, U. Jaeger, and P. Thoegersen, "Single current sensor technique in the DC link of three-phase PWM-VS inverters: A review and a novel solution," IEEE Trans. Ind. Appl., vol. 33, 1997.

[11] H.-G. Joo, M.J. Youn, and H.-B.Shin, "Estimation of phase currentsfrom a DC-Link current sensor using space vector PWM method," Electr.Mach. Power Syst., vol. 28, 2000. 